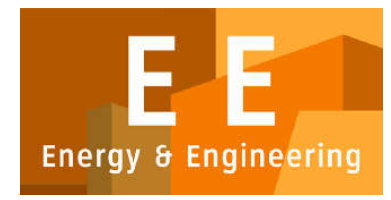

PAPER - OPEN ACCESS

\title{
Design of Work Safety Bracelet in Travelling
}

\author{
Author : Sarah Ratna Sari Panjaitan, dkk \\ DOI \\ : 10.32734/ee.v2i3.756 \\ Electronic ISSN $\quad: 2654-704 X$ \\ Print ISSN : $2654-7031$
}

Volume 2 Issue 3 - 2019 TALENTA Conference Series: Energy \& Engineering (EE)

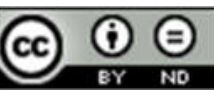

This work is licensed under a Creative Commons Attribution-NoDerivatives 4.0 International License.

Published under licence by TALENTA Publisher, Universitas Sumatera Utara

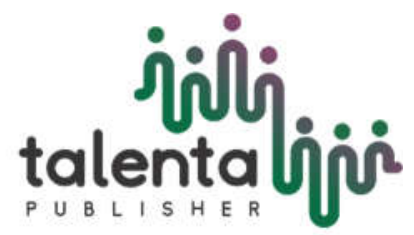




\title{
tolenthil hil hion TALENTA Conference Series
}

Available online at https://talentaconfseries.usu.ac.id

\section{Design of Work Safety Bracelet in Travelling}

\author{
Sarah Ratna Sari Panjaitan ${ }^{1}$, Maria Elfrida Sibuea ${ }^{2}$, Elserida Quinta Nababan ${ }^{3}$ \\ ${ }^{\text {I}}$ Fakultas Teknik, Universitas Sumatera Utara, Del Institute of Technology
}

1'sarahh.smadel@gmail.com, ${ }^{2}$ mariasibuea123@gmail.com, ${ }^{3}$ elseridanababan@gmail.com

\begin{abstract}
Abstrak
Kawasan Danau Toba telah dicanangkan oleh pemerintah menjadi salah satu dari 10 kawasan strategis pariwisata nasional. Taman Eden 100 merupakan salah satu objek wisata hutan yang di Lumbanrang, tepatnya di Kabupaten Toba Samosir yang merupakan salah satu kawasan dataran tinggi di Sumatera Utara. Berdasarkan hasil survei, saat melakukan penjelajahan, 43.1\% responden mengeluhkan bahwa kendala yang sering terjadi adalah tersesat karena tidak tahu peta lokasi, sistem jaringan komunikasi yang buruk, dan masalah keamanan. Produk Safety Bracelet (Saber) mempunyai potensi menjadi salah satu produk penjamin keselamatan saat melakukan penjelajahan. Namun hingga saat ini belum ditemukan produk penjamin keselamatan selain tour guide. Pembuatan rancangan produk hingga analisis kelayakan bisnis produk Safety Bracelet (Saber) bertujuan dalam pengembangan produk sebagai salah satu produk keselamatan. Perancangan produk dimulai dari Idea Generation, QFD, prototype design, dan studi kelayakan bisnis, yang dibutuhkan agar memudahkan pengembangan bisnis dan tidak adanya kemungkinan berhenti di tengah jalan saat bisnis dijalankan. Metode analisa yang digunakan adalah metode peramalan kualitatif dan kuantitatif untuk memprediksi peluang pasar. metodologi QFD yaitu "The House of Quality" untuk penentuan desain spesifikasi dan target respon teknis untuk proses produksi produk, rancangan produk keselamatan Saber hingga mendesain model bisnis dengan menggunakan teknologi tepat guna, dan metode analisis kelayakan investasi yaitu analisa aspek sosial, hukum, dan legalitas, serta Techno-Economics Analysis dengan menggunakan beberapa perhitungan seperti BEP, Cashflow, Payback Period, NPV, ROR, dan BCR.
\end{abstract}

Kata Kunci: Idea Generation, keselamatan, QFD

\begin{abstract}
The Lake Toba region has been declared by the government to be one of 10 national tourism strategic areas. Eden Park 100 is one of the forest tourism objects in Lumbanrang, precisely in Toba Samosir Regency which is one of the highlands in North Sumatra. Based on survey results, when exploring, $43.1 \%$ of respondents complained that the problem that often occurs is getting lost because they do not know the location map, bad communication network system, and security problems. Safety Bracelet (Saber) products have the potential to become one of the safety guarantor products when exploring. But so far no safety guarantor products have been found besides the tour guide. Making product design to business feasibility analysis Safety Bracelet (Saber) products aim at product development as a safety product. Product design starts from Idea Generation, QFD, prototype design, and business feasibility studies, which are needed to facilitate business development and there is no possibility of stopping halfway through when the business is run. The analytical method used is qualitative and quantitative forecasting methods to predict market opportunities. QFD methodology namely "The House of Quality" for determining the design specifications and technical response targets for the production process of products, design of Saber safety products to design business models using appropriate technology, and investment feasibility analysis methods, namely analysis of social, legal, and legal aspects, and Techno-Economics Analysis by using several calculations such as BEP, Cashflow, Payback Period, NPV, ROR, and BCR.
\end{abstract}

Keywords: Idea Generation, safety, QFD

(C) 2019 The Authors. Published by TALENTA Publisher Universitas Sumatera Utara

Selection and peer-review under responsibility of The 3nd National Conference on Industrial Engineering (NCIE)

2019

p-ISSN: 2654-7031, e-ISSN: 2654-704X, DOI: 10.32734/ee.v2i3.756 


\section{Pendahuluan}

Pariwisata bagi sebagian besar individu merupakan kebutuhan yang tidak terhindarkan. Pariwisata sendiri berasal dari bahasa Sanskerta (Musanef, 1995), bukanlah berarti "tourisme" (bahasa Belanda) atau tourism (bahasa Inggris). Selanjutnya pariwisata diartikan sebagai suatu perjalanan yang dilaksanakan untuk sementara waktu, yang dilakukan dari satu tempat ke tempat yang lain untuk menikmati perjalanan bertamasya dan berekreasi (Yoeti \& A, 1983).[1]. Kebutuhan hiburan mulai dari jalan-jalan ke berbagai tempat wisata hingga wisata kuliner menjadi tujuan utama di berbagai daerah. Begitu pula di wilayah Indonesia khususnya Toba Samosir.

Danau Toba merupakan objek wisata yang cukup terkenal di kalangan masyarakat sebagai Daerah Tujuan Wisata (DTW) lokal maupun mancanegara. Namun di sisi lain terdapat aset wisata alam yang indah dan sangat potensial juga untuk dikembangkan yaitu Taman Eden 100 yang berada di daerah Kabupaten Toba Samosir. Taman Eden 100 memiliki beragam spot/area seperti Tanaman Strawberry, Gua Kelelawar, Air Terjun, Pembudidayaan Tanaman.

Andaliman, Rumah Tarzan, berbagai jenis flora seperti Tahul-tahul (Nephenthes), Bunga Batak (Macodes petola), Bunga Soripada (Malakis sp), anggrek langka, serta ratusan jenis pohon berbuah dan berbagai fauna seperti ribuan kelelawar di dalam gua, burung, ikan, babi hutan, rusa, kupu-kupu, ihan batak, bahkan harimau sumatera dan binatang lainnya.[2].

Rata-rata jumlah pengunjung di objek wisata Taman Eden setiap tahunnya mencapai 15.000 orang (Sianipar, 2018). Menurut survei yang telah dilakukan kepada 44 responden yang pernah berkunjung ke Taman Eden 100, kebanyakan pengunjung berasal dari kalangan usia 17 hingga 24 tahun Melihat besarnya jumlah pengunjung setiap tahunnya di Taman Eden 100 dan berasal dari kalangan usia yang tergolong muda, dapat dijadikan sebagai peluang yang besar untuk mengembangkan kegiatan outdoor seperti area hiking dan camping ground yang telah ada sebelumnya di area tersebut. Namun, yang menjadi masalah dalam pengembangan kegiatan ini adalah belum adanya fasilitas yang memadai untuk kegiatan ini sehingga menimbulkan beberapa kendala bagi para pengunjung.[3].

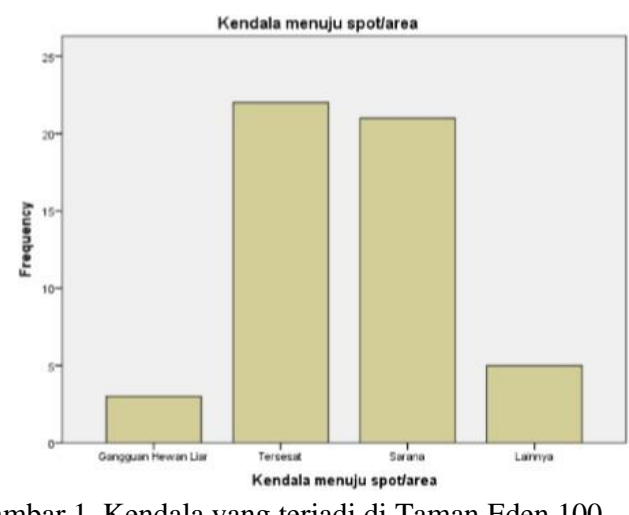

Gambar 1. Kendala yang terjadi di Taman Eden 100

Berdasarkan hasil survei dari 51 responden yang tidak hanya sekali berkunjung ke Taman Eden 100, sebanyak 43.1\% mengeluhkan bahwa kendala yang sering terjadi adalah tersesat saat berada pada lokasi tersebut. Kendala ini disebabkan oleh beberapa hal seperti pada Tabel 1.

Tabel 1. Penyebab Tersesat di Taman Eden 100

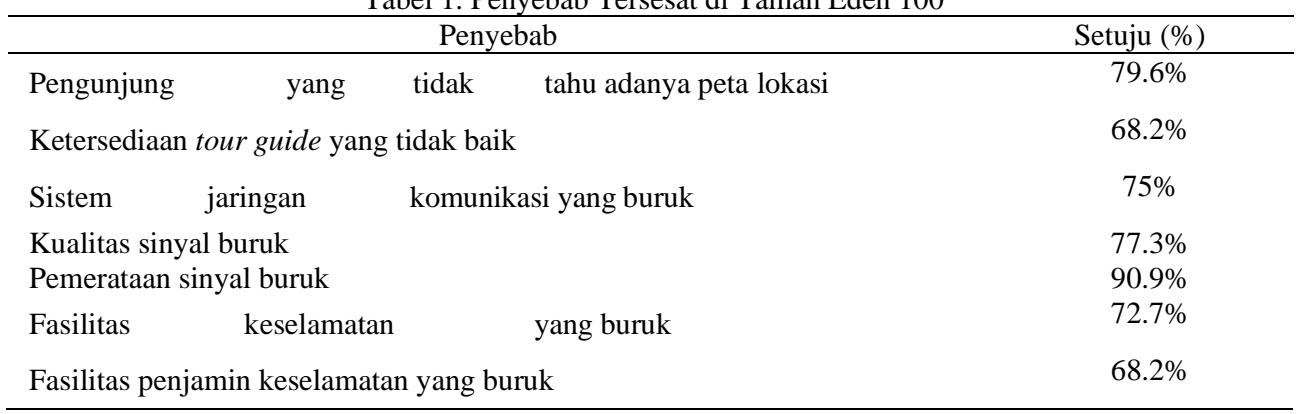

Oleh sebab itu, berdasarkan adanya beberapa penyebab yang menjadi akar masalah terjadinya kesesatan saat melakukan kegiatan outdoor, maka penulis bertujuan untuk merumuskan produk safety bracelet yang dapat mengetahui keberadaan pengunjung dan mencegah terjadinya kehilangan rekan saat melakukan kegiatan outdoor, 
dengan memanfaatkan layanan bluetooth mengingat pemerataan sinyal yang tidak baik di daerah Taman Eden 100.[4].

\section{Metodologi Penelitian}

\subsection{Quality Functional Deployment (QFD)}

Quality Function Deployment (QFD) adalah suatu metodologi terstruktur yang digunakan dalam proses perencanaan dan pengembangan produk untuk menetapkan spesifikasi kebutuhan dan keinginan konsumen, serta mengevaluasi secara sistematis kapabilitas suatu produk atau jasa dalam memenuhi kebutuhan dan keinginan konsumen.[5].

Terdapat atribut kebutuhan konsumen yang menjadi faktor penentu tingkat kepuasan konsumen terhadap produk Safety Bracelet, dapat dilihat pada tabel 2.

\begin{tabular}{cc}
\multicolumn{2}{c}{ Tabel 2. Atribut produk Safety Bracelet } \\
\hline No & Atribut produk \\
\hline 1 & Jangkauan Radial \\
2 & Kenyamanan \\
3 & Durabilitas \\
4 & Harga \\
5 & Baterai tahan lama \\
6 & Ringan \\
7 & Getaran kuat \\
8 & Desain minimalis \\
9 & Ukuran \\
10 & Warna \\
11 & cpMudah digunakan \\
12 & Suara \\
13 & Tahan air \\
\hline
\end{tabular}

Untuk mengetahui spesikasi dan respon teknis perusahaan terhadap masing-masing atribut produk, maka respon teknis yang dibutuhkan dapat dilihat seperti tabel 3.

Tabel 3. Karakteristik teknis produk Saber

\begin{tabular}{cc}
\hline No & Respon Teknis \\
\hline 1 & Pemilihan material \\
2 & Pengukuran produk \\
3 & Instalasi arduino \\
4 & Coding \\
5 & Pemilihan baterai \\
6 & Pemilihan komponen \\
7 & Desain produk \\
\hline
\end{tabular}

Terdapat tanda atau matriks yang menunjukkan korelasi antara atribut produk dengan respon teknisnya. Dimana antara atribut dan respon teknis, terdapat matriks yang menunjukkan hubungan kuat( $\bullet$ ), hubungan $\operatorname{sedang}(\circ)$, dan hubungan lemah $(\nabla)$. Dapat dilihat pada gambar 2. 


\begin{tabular}{|c|c|c|c|c|c|c|c|c|c|}
\hline 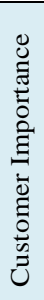 & 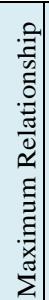 & $\begin{array}{l}\text { Customer Requirements } \\
\text { (Explicit and Implicit) }\end{array}$ & 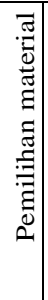 & 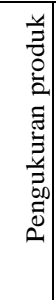 & 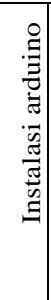 & 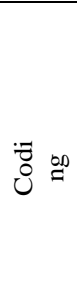 & 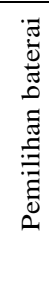 & 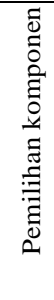 & 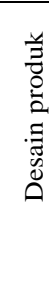 \\
\hline 5 & 9 & Jangkauan Radial & & & - & • & & & \\
\hline 4 & 9 & Kenyamanan & $\bullet$ & ० & & $\nabla$ & & & \\
\hline 3 & 9 & Durabilitas & $\bullet$ & & & & & & \\
\hline 3 & 9 & Harga & ० & $\nabla$ & $\bullet$ & & ० & $\bullet$ & \\
\hline 4 & 9 & Baterai tahan lama & & & ○ & & $\bullet$ & $\bullet$ & \\
\hline 3 & 9 & Ringan & $\bullet$ & & & & & & \\
\hline 3 & 3 & Getaran kuat & & & ० & $\circ$ & & & \\
\hline 4 & 9 & Desain minimalis & & $\nabla$ & o & & & & $\bullet$ \\
\hline 2 & 9 & Ukuran & & - & & & & & $\bullet$ \\
\hline 2 & 1 & Warna & $\nabla$ & & & & & & \\
\hline 3 & 3 & Mudah digunakan & & 0 & & & & & ० \\
\hline 5 & 3 & Suara & & & $\circ$ & $\circ$ & & & \\
\hline 4 & 9 & Tahan air & $\bullet$ & & & & & 0 & \\
\hline
\end{tabular}

Gambar 2. Matriks antara atribut produk dan karakteristik teknis Safety Bracelet

\subsection{Desain Safety Bracelet (Saber)}

Pada pembuatan desain produk, ukuran dan dimensi yang sesuai dengan desain rancangan prototype Safety Bracelet. Proses pembuatannya, dimulai dari material yang sudah tiba di pabrik akan disortir berdasarkan jenisnya. Papan Printed Circuit Board (PCB), digunakan sebagai dudukan komponen. Komponen utama yang diinstal di PCB adalah chipset, diikuti dengan Modul Bluetooth, terinstall akan di tautkan ke dial, dengan posisi lampu menghadap keluar yang berasal dari dial yang sudah dilubangi di bagian tengahnya. Setelah itu, komponen akan dihubungkan ke sumber daya berupa baterai.

Bagian penutup/pelindung (casing) terbuat dari karet dan besi. Besi digunakan karena sifat materialnya yang keras dan baku sementara karet digunakan karena sifatnya yang lentur, nyaman, dan bisa menyesuaikan dengan lengan pengguna. Iron casing yang di outsource dari vendornya sudah berbentuk persegi panjang dengan dimensi panjang, lebar, dan tinggi. Iron casing ini menjadi wadah bagi komponen-komponen utama. Bagian atas casing masih terbuka, oleh karena itu perlu ditutup dengan menggunakan kaca yang sudah dibersihkan sebelumnya. Badan alat yang sudah terinstall akan diinstall dengan strap karet sehingga bisa dikenakan. Produk yang sudah jadi harus melewati inspeksi terakhir sebelumnya disimpan di penyimpanan/inventori.[6]. 
Berikut ini adalah rancangan produk Safety Bracelet yang ditunjukkan pada gambar 4.

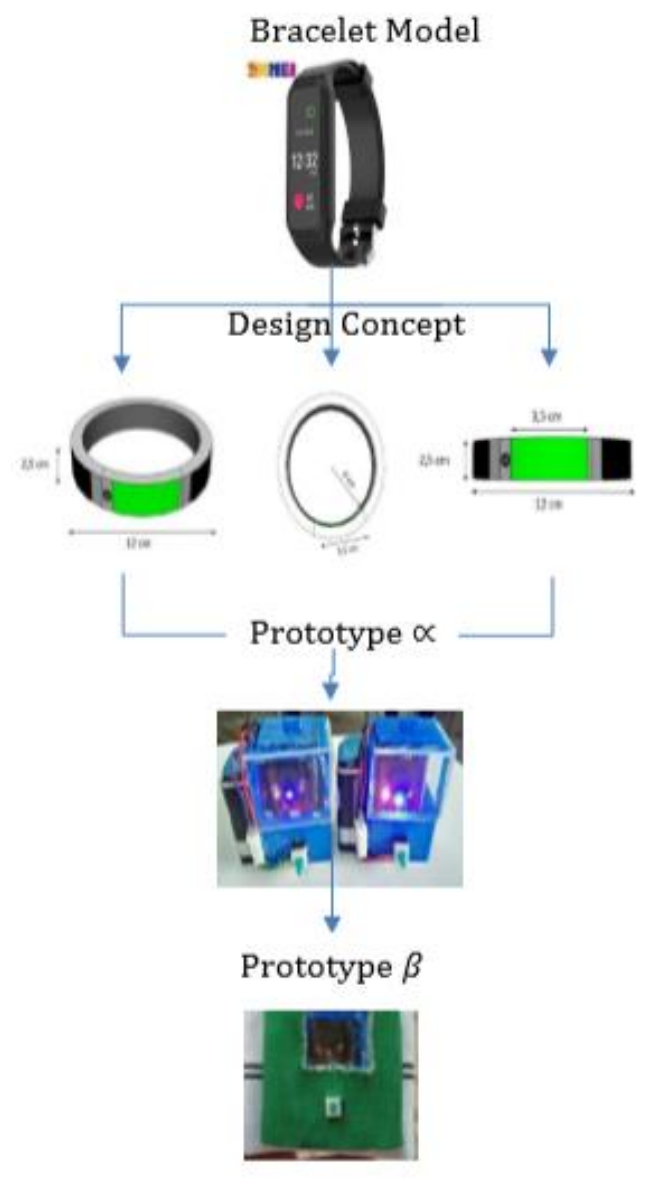

Gambar 3. Desain Prototype Safety Bracelet

Sebelum produk safety bracelet di-running maka dilakukan pengujian. Pengujian dilakukan terhadap dua user Safety Bracelet dalam keadaan standby dicirikan dengan lampu LED berwarna biru. Setelah itu, jangkauan radial diuji dengan memisahkan kedua user dengan jarak tertentu. Hasil pengujian adalah valid, dimana lampu LED produk Safety Bracelet berfungsi sesuai konsep desain yaitu berubah menjadi merah dan mengeluarkan bunyi saat kedua user terpisah dalam jarak $20 \mathrm{~m}$.

\subsection{Uji Kelayakan Bisnis (Feasibility Study)}

Kajian kelayakan bisnis pada pembuatan produk Saber ditinjau dari segi sosial, politik, dan finansial. Faktor sosial berupa perubahan gaya hidup pengguna yang cenderung menggunakan produk praktis, gampang dibawa kemana-mana, aman digunakan, memiliki fungsionalitas yang sesuai dan desain yang menarik berdampak pada pertumbuhan bisnis yang akan didirikan. Faktor politik berupa situasi politik dapat diketahui melalui berita-berita, media massa, dan isu-isu publik. Aspek politik pemerintah diantaranya peraturan perundang-undangan, perjanjian perdagangan internasional dan nasional, hukum perlindungan secara langsung maupun tidak langsung memengaruhi kelayakan bisnis Safety Bracelet. Faktor finansial berupa biaya-biaya yang diperlukan dimana biaya tersebut dibedakan menjadi capex dan opex. Biaya CAPEX tersebut merupakan komponen yang dibutuhkan dan biaya produksi produk dengan masa waktu produksi selama 15 tahun, sedangkan biaya OPEX tersebut merupakan biaya untuk melakukan produksi selama 15 tahun. Biaya bahan baku yang digunakan untuk membuat saber dapat dilihat pada tabel 4 . 
Tabel 4. Capex dan Opex Safety Bracelet

\begin{tabular}{|c|c|c|c|c|c|}
\hline No & Nama & Quantity & Satuan & Harga/satuan & Total \\
\hline & & & & $\mathrm{Rp}$ & $\mathrm{Rp}$ \\
\hline 1 & Chipset & 1 & Buah & $\begin{array}{c}40,000.00 \\
\mathrm{Rp}\end{array}$ & $\begin{array}{c}40,000.00 \\
\mathrm{Rp}\end{array}$ \\
\hline 2 & Baterai LR41 & 1 & Buah & $\begin{array}{c}5,000.00 \\
\mathrm{Rp}\end{array}$ & $\begin{array}{c}5,000.00 \\
\mathrm{Rp}\end{array}$ \\
\hline 3 & PCB & 1 & Buah & $\begin{array}{c}15,000.00 \\
\mathrm{Rp}\end{array}$ & $\begin{array}{c}15,000.00 \\
\mathrm{Rp}\end{array}$ \\
\hline 4 & Module Radio & 1 & Buah & $\begin{array}{c}25,000.00 \\
\mathrm{Rp}\end{array}$ & $\begin{array}{c}25,000.00 \\
\mathrm{Rp}\end{array}$ \\
\hline 5 & Module Bluetooth & 1 & Buah & $\begin{array}{c}20,000.00 \\
\mathrm{Rp}\end{array}$ & $\begin{array}{c}20,000.00 \\
\text { Rp }\end{array}$ \\
\hline 6 & $\begin{array}{c}\text { Lampu LED } \\
\text { Hollow }\end{array}$ & 2 & Buah & $\begin{array}{c}1,000.00 \\
\mathrm{Rp}\end{array}$ & $\begin{array}{c}2,000.00 \\
\mathrm{Rp}\end{array}$ \\
\hline 7 & Aluminium & 0.035 & Meter & $\begin{array}{c}30,000.00 \\
\mathrm{Rp}\end{array}$ & $\begin{array}{c}1,050.00 \\
\mathrm{Rp}\end{array}$ \\
\hline 8 & Besi & 0.02 & Meter & $\begin{array}{c}5,000.00 \\
\mathrm{Rp}\end{array}$ & $\begin{array}{c}100.00 \\
\mathrm{Rp}\end{array}$ \\
\hline 9 & Kaca jam tangan & 0.035 & Meter & $\begin{array}{c}1,000.00 \\
\mathrm{Rp}\end{array}$ & $\begin{array}{c}35.00 \\
\mathrm{Rp}\end{array}$ \\
\hline 10 & Rubber & 0.35 & Meter & $\begin{array}{c}8,000.00 \\
\mathrm{Rp}\end{array}$ & $\begin{array}{c}2,800.00 \\
\mathrm{Rp}\end{array}$ \\
\hline 11 & Vibrator & 1 & Buah & $\begin{array}{c}18,000.00 \\
\mathrm{Rp}\end{array}$ & $\begin{array}{c}18,000.00 \\
\mathrm{Rp}\end{array}$ \\
\hline 12 & Baut Jam tangan & 4 & Buah & $\begin{array}{c}250.00 \\
\mathrm{Rp}\end{array}$ & $\begin{array}{c}1,000.00 \\
\mathrm{Rp}\end{array}$ \\
\hline 13 & Kotak $(15 \times 5)$ & 1 & Buah & $3,000.00$ & $3,000.00$ \\
\hline
\end{tabular}

Selain tiga faktor diatas, Instrumen kelayakan bisnis pada pembuatan saber menggunakan pertimbangan dengan melakukan analisis aspek ekonomi seperti BEP, Cashflow,Payback Period(PP) NPV, ROR, dan BCR dapat dilihat pada tabel.

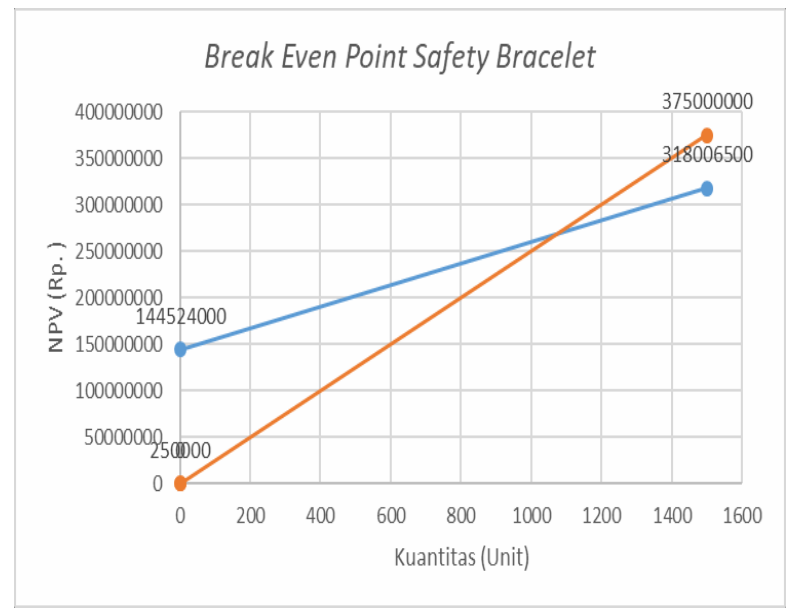

Gambar 4. Break Even Point Safety Bracelet

Tabel 5. Analisis Kelayakan Bisnis Saber

\begin{tabular}{cccc}
\hline Metode Penilaian & Hasil & Kriter ia & Penilai an \\
\hline NPV & Rp 11,649,891,824 & Positif & Layak \\
ROR & $30.43 \%$ & ROR $>0$ & Layak \\
BCR & 1.437 & BCR $>1$ & Layak \\
\hline
\end{tabular}




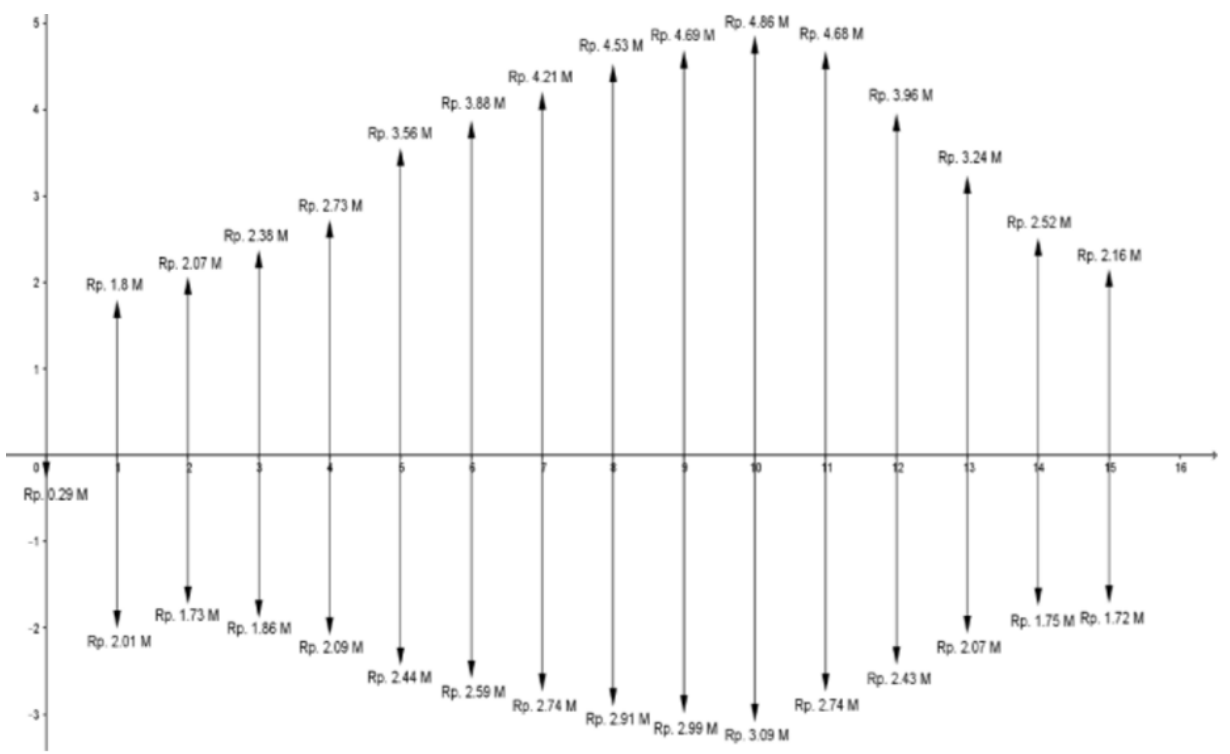

Gambar 5. Cashflow Diagram Safety Bracelet

Berdasarkan analisis kelayakan bisnis Safety Bracelet, NPV untuk periode 15 tahun didapat sebesar Rp 11,649,891,824,- yang berasal dari tingkat suku 3,5\% inflasi dan risiko.

Bisnis ini akan balik modal saat mencapai tingkat BEP(Break Even Unit) sebesar 1076 unit pada tahun pertama bulan kedua dengan tingkat ROR sebesar 30.43\% dan NPV Rp 11,649,891,824 dan rasio BCR sebesar 1.437. Bisnis Safety Bracelet tidak sensitif terhadap perubahan income, tingkat suku bunga dan outcome.

\section{Kesimpulan dan Saran}

Berdasarkan analisis desain dan kelayakan produk Safety Bracelet maka dapat disimpulkan bahwa :

1. Analisis pasar dan pemasaran Produk Safety Bracelet merupakan produk yang memiliki prospek pasar yang cukup besar dalam melakukan penjelajahan ke hutan dan mencegah terjadinya kesesatan saat melakukan kegiatan outdoor dengan memanfaatkan layanan bluetooth mengingat pemerataan sinyal yang tidak baik.

2. Dilihat dari analisa aspek teknis, produk Safety Bracelet menunjukkan bahwa jangkauan radial, baterai tahan lama, pemilihan material dan desain minimalis sangat berpengaruh terhadap kenyamanan konsumen.

3. Berdasarkan analisa finansial yang telah dilakukan, dapat disimpulkan bahwa dengan tingkat suku bunga 3,5\% dihasilkan nilai optimum NPV Rp11.794.415.824,-, Payback Period (PP) ditahun pertama, BEP 1067 Unit (2 bulan), rasio BCR sebesar 1.437. Bisnis Safety Bracelet tidak sensitive terhadap perubahan income, tingkat suku bunga dan outcome.

4. Bisnis SafetyBracelet menguntungkan secara finansial.

\section{Referensi}

[1] Musanef. (1995). Manajemen Pariwisata di Indonesia. Jakarta: Gunung Harta

[2] Sianipar, M. (2018). Dalam O. A. Analisis Strategi Pengembangan Obyek Wisata Alam di Kabupaten Toba Samosir dengan Analisis SOAR (Strength)

[3] Yoeti, \& A, O. (1983). Dalam P. I. Pariwisata. Bandung: Angkasa

[4] Apple, J.M. 1990. TataLetak Pabrik dan Pemindahan Bahan. Edisi Ketiga. ITB.

[5] Batubara, Siti Chairiyah. 2016. Disain Sistem Manajemen Rantai Pasokan Industri Perikanan Tangkap Laut Berkelanjutan. Disertasi. Bogor: Institut Pertanian Bogor.

[6] Purnomo, Bambang Hari., dkk. 2011. Model Prediksi Keberlanjutan Sumber Daya Dan Ekonomi Pada Agroindustri Teri Nasi. Jurnal Teknologi Industri Pertanian. 